\title{
Millimeter Waves Frequency Reconfigurable Antenna for 5G Networks
}

\author{
FAROOQ AZAM*, SHAHID BASHIR*, AND MUHAMMAD AMMAR SOHAIB* \\ RECEIVED ON 21.03.2018 ACCEPTED ON 17.08.2018
}

\begin{abstract}
5G (Fifth Generation) is the next generation of data network, offering faster speeds and reliable connections on smart phones and other devices than ever before. These networks are still under development and expected to operate on 28 and 38GHz bands. However, multiple antennas required for these $5 \mathrm{G}$ devices will increase the overall system size. Single antenna which can switch to operate on multiple bands is the solution to this problem. A novel frequency reconfigurable antenna for $5 \mathrm{G}$ communication networks is presented in this paper. The antenna was designed on a Roger R5880 substrate having dielectric constant 2.2 and loss tangent 0.0009 . The proposed antenna consists of simple radiator on top layer and two slots in the ground layer. The frequency re-configurability is achieved by placing three PIN diodes in each slot of the ground. The operating frequency band of antenna is controlled by switching states of PIN diodes. The proposed antenna covers a wide band from 25.6-39.3 GHz by simply switching the diodes ON/OFF. Thus it can cover 28 and $38 \mathrm{GHz}$ bands that are anticipated to be the two working bands for 5G communication. The overall size of the antenna is $10 \times 7 \mathrm{~mm}^{2}$. In addition to being small this antenna has a good gain ranging from 6.5-8.4 dB as well as $85 \%$ efficiency in the two $5 \mathrm{G}$ bands. All simulations have been done in CST (Computer Simulation Technology) Studio Suite. This reconfigurable antenna can find applications in future $5 \mathrm{G}$ communication networks.
\end{abstract}

Key Words: Reconfigurable Antenna, 5G Communication, Millimeter-Waves, Wide-Band, MultipleInput and Multiple-Output System, Pin Diodes.

\section{INTRODUCTION}

I

n the last few decades tremendous changes have been observed in communication technologies and specifically in wireless communication. Keeping in view with such changes operators introduced advanced generations from time to time. It all started in 1980's with the introduction of 1G, 2G in 1990's, 3G in 2001 and 4G since 2010. Next ambition is 5G deployment and is believed to be launched in 2020 [1].
Keeping in mind the existing day traffic and data rate requirements, moving to higher frequencies is the only option left for the wireless technology operators. As such frequency bands offer higher data rates and spectral capacity presently needed. It is expected to reach to true Giga-bytes data rate in $\mathrm{mm}$ (millimeter) wave spectrum and its range is from 30-300 GHz [2-3]. The main drawback while operating in mm wave is that path loses are greater,

Authors E-Mail: (farooqazam89@gmail.com, shahid.bashir@uetpeshawar.edu.pk, mast2126@gmail.com)

*Department of Electrical Engineering, University of Engineering \& Technology, Peshawar, Pakistan. 
signal attenuates easily and signal can rain fade as well [4]. Comparing it with below $3 \mathrm{GHz}$ band in which a signal can travel miles penetrating buildings whereas in mm wave a signal is even absorbed by an oxygen molecule [5].

For different frequencies the signal attenuation and path losses are different which is validated by many studies. For a distance less than a km, the effect of rain attenuation will be least while operating in $28 / 38 \mathrm{GHz}$ [6]. Also the game changer for $5 \mathrm{G}$ is the use of MIMO (Multiple-Input and Multiple-Output) technique which will make long distance communication possible. Designing an antenna for MIMO systems, volume and dimensions of antenna individually plus overall system size must be taken into consideration. The size of the overall system will increase if a conventional antenna is used in MIMO. As specific antenna will be required to tackle each varying scenario, so by substituting many antennas with a single reconfigurable antenna is the solution. Reconfigurable antennas have attracted attention especially in wireless technology since last decade. Reconfigurable antenna has the ability to adjust dynamically some of its basic parameters like frequency, radiation pattern, polarization and in some cases all of them simultaneously [7].

Frequency reconfigurable antennas are suitable for wireless industry due to the characteristic that it can hop between different frequencies as per need. It has additional advantage that it operates on only those frequencies that are needed, switching off the rest and so reducing co-site interference. A single reconfigurable antenna can even switch its frequency in between nine modes [8]. Operating on single or dual bands a conventional antenna design mostly covers only a small band. By adding few modifications to these simple antennas make it adoptable and so can be made to operate on multiple frequencies. By using different methods of reconfiguration a simple T, $\mathrm{U}$, Fork shape or even a patch antenna can be made reconfigurable [9-11].

Some of the basic techniques to achieve re-configurability are RF-MEMS (Radio Frequency Microelectromechanical System) switches [12-13], Varactors switches [14], PIN Diodes [15-16] FET switches [17] and optical switches [18]. MEMS (Micro-Electro-Mechanical Systems) switches have better isolation, power losses are less and DC consumption very low. But MEMS have disadvantages such as speed of switching is slow, life cycle is short and are less reliable as mechanical motion is involved. Compared to PIN diodes and MEMs current through varactors is low but it needs a complex bias circuitry and has low dynamic range. Looking into pros and cons of the electric switches used for reconfigurability PIN diodes best suit our design.

For our proposed design PIN diodes are chosen as driving voltage is very low and have high switching speed between ON/OFF states. It also has high power handling potential, very economical and as no moving parts are involved so has high reliability [19]. Equivalent circuit of PIN diode MA4AGFCP910 has been used for ON/OFF state. Nowadays PIN diodes are available, which can operate at mm wave frequency with isolation of $20 \mathrm{~dB}$ in ON state and maximum insertion loss of $1 \mathrm{~dB}$ in OFF state.

The novelty of proposed design lies in the unique topology of PIN diodes connection. This connection topology helps in controlling the operating frequency over a wide range. Moreover, the proposed antenna can support most of the prospective $5 \mathrm{G}$ bands i.e. 26,28 and

Mehran University Research Journal of Engineering \& Technology, Volume 38, No. 3, July, 2019 [p-ISSN: 0254-7821, e-ISSN: 2413-7219] 
$38 \mathrm{GHz}$. The proposed design is modelled and simulated in CST Microwave Studio [20].

\section{METHODOLOGY}

The design of the proposed reconfigurable antenna is shown in Fig. 1. The basic antenna design is a simple patch. All labeled dimensions are in $\mathrm{mm}$. The antenna was designed on a R5880 substrate having dielectric constant 2.2 and loss tangent 0.0009 . The patch was fed using inset feed coupling technique.

The back view of the antenna under the patch is shown in Fig. 2. A conventional rectangular patch antenna has been modified into a reconfigurable antenna by making two slots in the ground and then inserting six PIN diodes in between the slots. The length of the slot was kept same as that of patch whereas the width size was kept $1.5 \mathrm{~mm}$. Three diodes were placed in each slot at a fixed distance from each other. Diodes 1, 2 and 3 were placed in

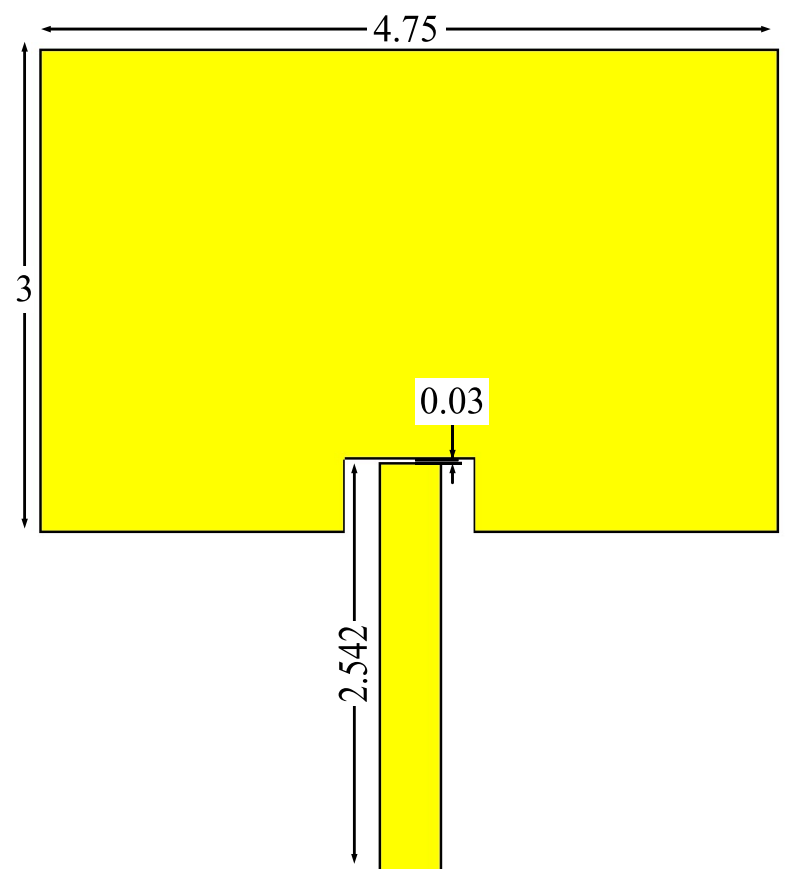

FIG. 1. FRONT VIEW OF FEED AND PATCH the upper slot whereas diodes 4,5 and 6 were fixed in the lower one. The Diode 1, 3, 4 and 6 were $1.5 \mathrm{~mm}$ from the center horizontally and $0.5 \mathrm{~mm}$ vertically. Diode 2 and 5 were placed in the middle of slots.

The length and width of the substrate and the ground were kept the same. The substrate thickness is $0.381 \mathrm{~mm}$ where as that of ground is $0.1 \mathrm{~mm}$. The antenna dimensions are $10.72 \times 7.24 \mathrm{~mm}$. The overall parameters of the antenna are shown in Table 1.

For simulation purposes equivalent circuit of PIN diodes shown in Fig. 3(a-b) has been used in the model. Its data sheet shows that the series resistance is $4.2 \Omega$ at $10 \mathrm{GHz}$ and the maximum series inductance value is $0.5 \mathrm{n}-\mathrm{H}$ for ON state. For OFF state it offers capacitance of $21 \mathrm{pF}$ and the shunt resistance value is $3 \mathrm{~K} \Omega$.

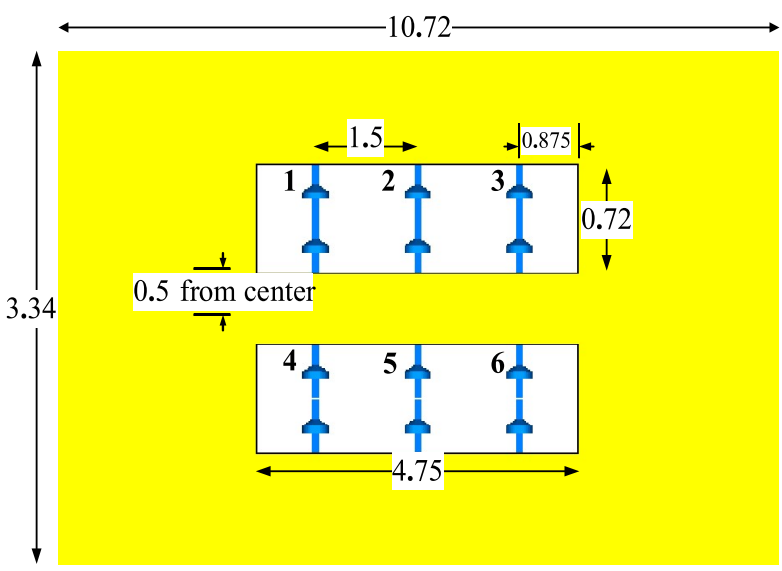

FIG. 2. BACK VIEW OF ANTENNA BELOW PATCH

TABLE 1. DESIGN PARAMETERS

\begin{tabular}{|c|c|}
\hline Parameter & Values (mm) \\
\hline Substrate Length & 7.24 \\
\hline Substrate Width & 10.72 \\
\hline Feed Length & 2.542 \\
\hline Feed Width & 0.789 \\
\hline Patch Length & 3.0 \\
\hline Patch Width & 4.75 \\
\hline Substrate Dielectric Constant & 2.2 \\
\hline
\end{tabular}


Length of the slot is the basic ingredient behind frequency hopping. This length is actually controlled by the ON/ OFF state of the diodes. In ON state the diodes act as short circuit so the slot effective area is decreased resulting in the antenna resonating at higher frequencies. In OFF state the diodes act as open circuit resulting in an increase in the slot area making the antenna shift to lower frequencies.

\section{RESULTS AND DISCUSSION}

As mentioned earlier all simulation have been done in CST studio suite. The desired results have been achieved by first designing a patch antenna and then modifying it to be reconfigurable. The diodes were simulated by putting equivalent circuit modal using lump elements option. The results support that reconfiguration has been achieved at different switch states. The performance of antenna is analyzed in this section by discussing parameters such as radiation pattern, return loss, gain and efficiency one by one.
The return loss of proposed antennas is shown in Fig. 4. With change in the state of an individual diode out of the six, resonant frequency is shifted. Fig. 4 shows four states which are most handy and cover an overall wide band of 13.75GHz. Its return loss is acceptable from 25.6-39.3 GHz. The proposed antenna can thus support most of the prospective $5 \mathrm{G}$ bands i.e. 26, 28 and $38 \mathrm{GHz}$. Four different modes as well as the frequency bands of these modes can be seen in Table 2.

The position of PIN diodes and size of patch can easily be parametrized to tune antenna to a different set of resonant frequencies. The radiation pattern of proposed reconfigurable antenna is shown in Figs. 5-6 for different frequencies. For the azimuth plane at $28 \mathrm{GHz}$ the antenna has a HPBW of $118^{\circ}$ with side lobe level $-3.1 \mathrm{~dB}$ and main beam direction is $358^{\circ}$ as shown in Fig. 5(a). Whereas for the elevation plane at $28 \mathrm{GHz}$ the antenna has a HPBW of $72^{\circ}$ and main beam direction at $6.78^{\circ}$ as shown in Fig. 5(b).

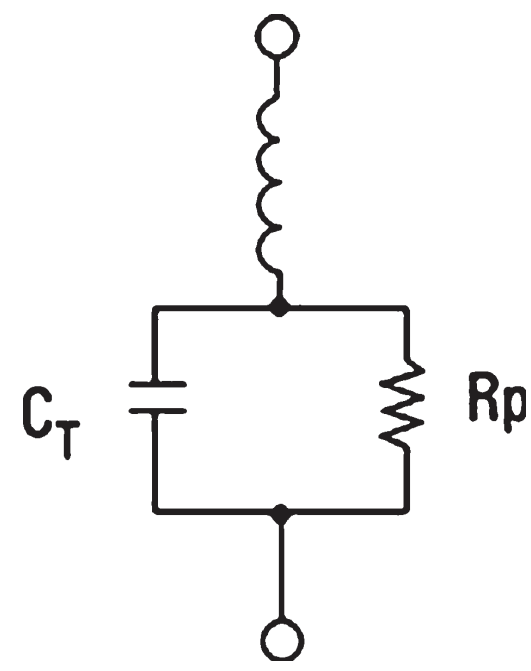

(b) OFF STATE

(a) ON STATE

FIG. 3. EQUIVALENT CIRCUITS OF PIN DIODE

Mehran University Research Journal of Engineering \& Technology, Volume 38, No. 3, July, 2019 [p-ISSN: 0254-7821, e-ISSN: 2413-7219] 
For azimuth plane radiation pattern at $38 \mathrm{GHz}$ the HPBW is $37^{\circ}$ and $62^{\circ}$ main beam direction. For the elevation plane at $38 \mathrm{GHz}$ the $\mathrm{HPBW}$ is $43^{\circ}$, main beam direction and magnitude is $33^{\circ}$ and $6.71 \mathrm{~dB}$ respectively as shown in Fig. 6(a-b).

The antenna total efficiency is shown in Fig. 7. The efficiency ranges from $88-96 \%$ at different frequencies for mode 1 . For other modes it has almost same range. The maximum efficiency is $95 \%$ at $28 \mathrm{GHz}$.
The antenna has quite good gain and it ranges from 5.4$8.4 \mathrm{~dB}$ as shown in Fig. 8. The maximum gain is $8.4 \mathrm{~dB}$ at 33 $\mathrm{GHz}$ in Mode-1. For other modes it has almost same range of values. For mode 4 it has a range of 5.5-8.2dB and has a maximum value at $32 \mathrm{GHz}$. For Mode- 2 its gain ranges from 5.4-7.8 GHz.

3D far field pattern at $28 \mathrm{GHz}$ is shown in Fig. 9. It shows a maximum gain of $7.22 \mathrm{~dB}$ gain at broadside direction.

For $38 \mathrm{GHz}$ the 3D far field pattern is shown in Fig. 10 which shows a gain of $7.15 \mathrm{~dB}$.

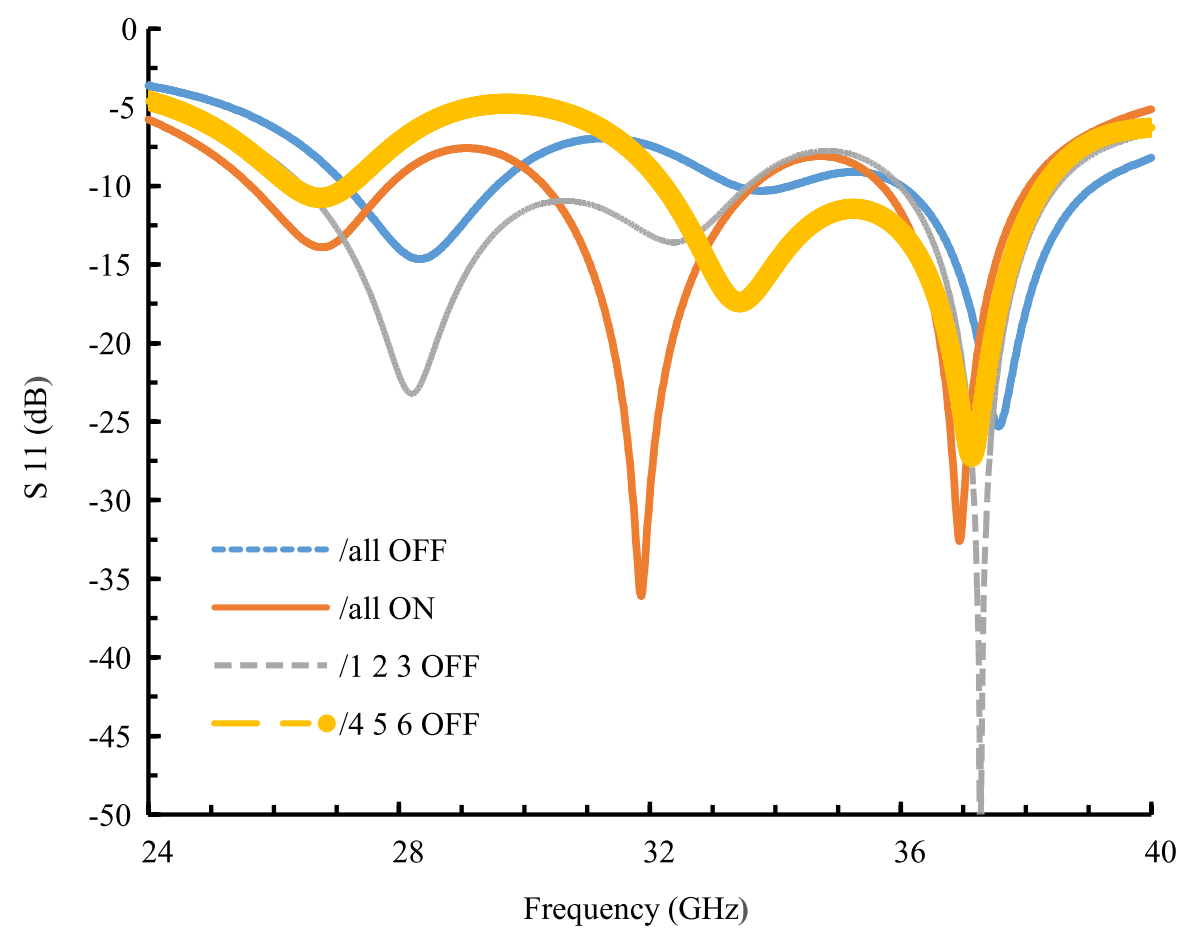

FIG. 4. RETURN LOSS FOR FOUR MOST USEFUL STATES OF DIODES

TABLE 2. FREQUENCY RECONFIGURABILITY FOR DIFFERENT SWITCH STATES

\begin{tabular}{|c|c|c|c|c|c|c|c|}
\hline Mode & D1 & D2 & D3 & D4 & D5 & D6 & Frequency (GHz) \\
\hline 1 & OFF & OFF & OFF & OFF & OFF & OFF & $27.1-29.7$ and $36.1-39.3$ \\
\hline 2 & ON & ON & ON & ON & ON & ON & $25.6-27.9$ and $30.2-33.6$ \\
\hline 3 & ON & ON & ON & OFF & OFF & OFF & $26.5-27.9$ and $32.3-38.5$ \\
\hline 4 & OFF & OFF & OFF & ON & ON & ON & $26.4-33.6$ and $36.1-38.5$ \\
\hline
\end{tabular}

Mehran University Research Journal of Engineering \& Technology, Volume 38, No. 3, July, 2019 [p-ISSN: 0254-7821, e-ISSN: 2413-7219] 


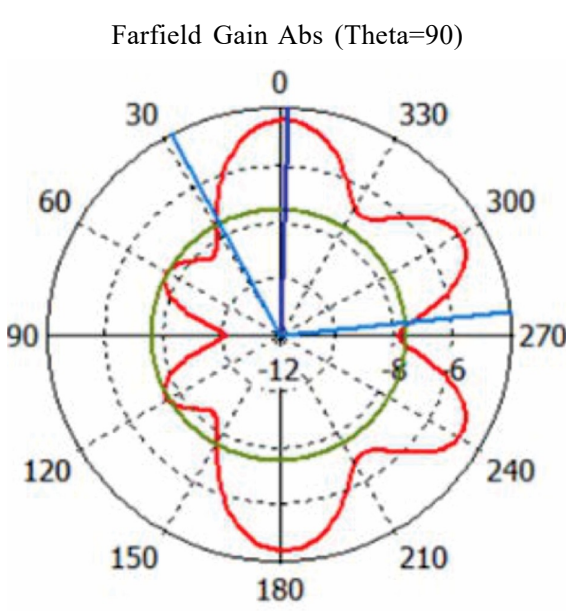

Phi/Degree vs. dB

(a) AZIMUTH PLANE

Farfield Gain Abs (Theta=90)

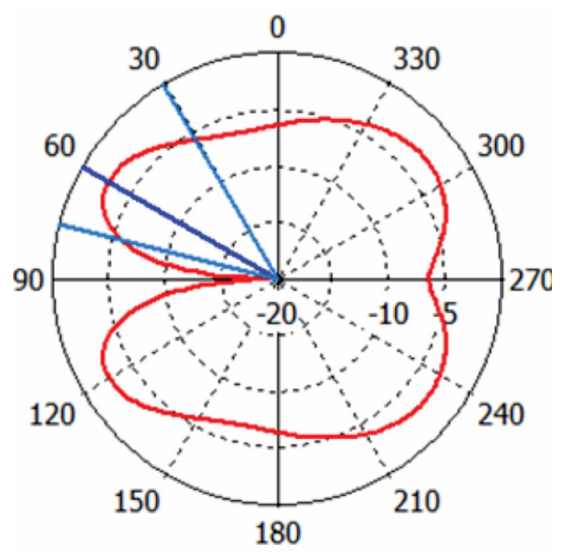

Farfield Gain Abs (Phi=90)

(a) AZIMUTH PLANE

FIG. 5. POLAR PLOTS AT $28 G H Z$

Farfield Gain Abs $(\mathrm{Phi}=90)$

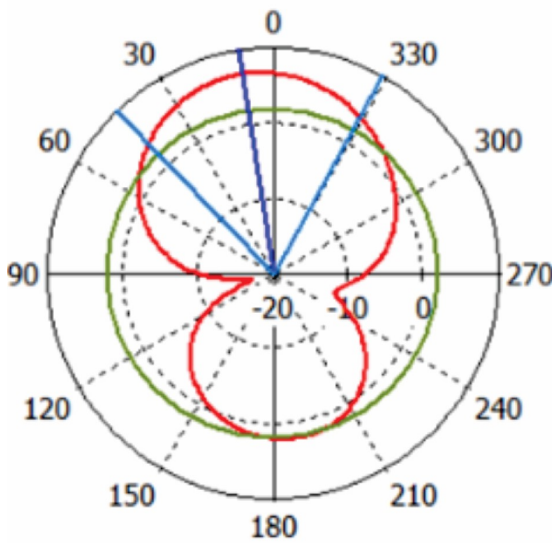

Theta/Degree vs. dB

(b) ELEVATION PLANE Phi/Degree vs. dB

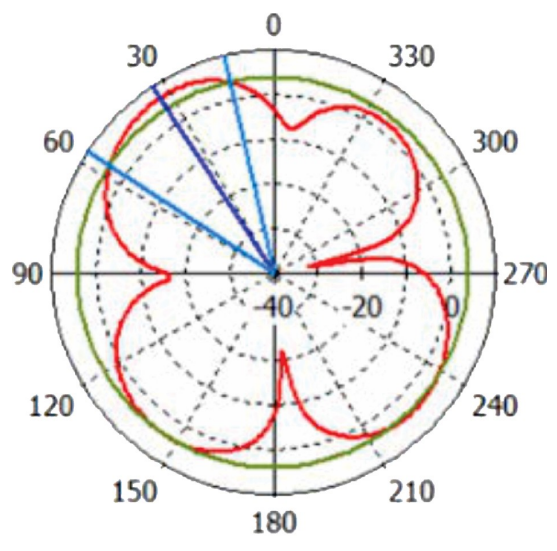

Theta/Degree vs. dB

(b) ELEVATION PLANE

FIG. 6. POLAR PLOTS AT 38GHZ

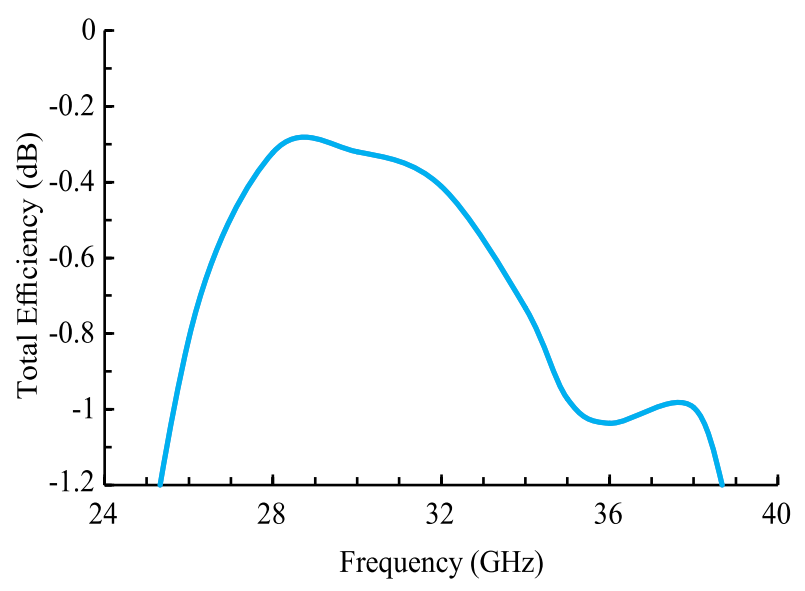

FIG. 7. TOTAL EFFICIENCY VS FREQUENCY

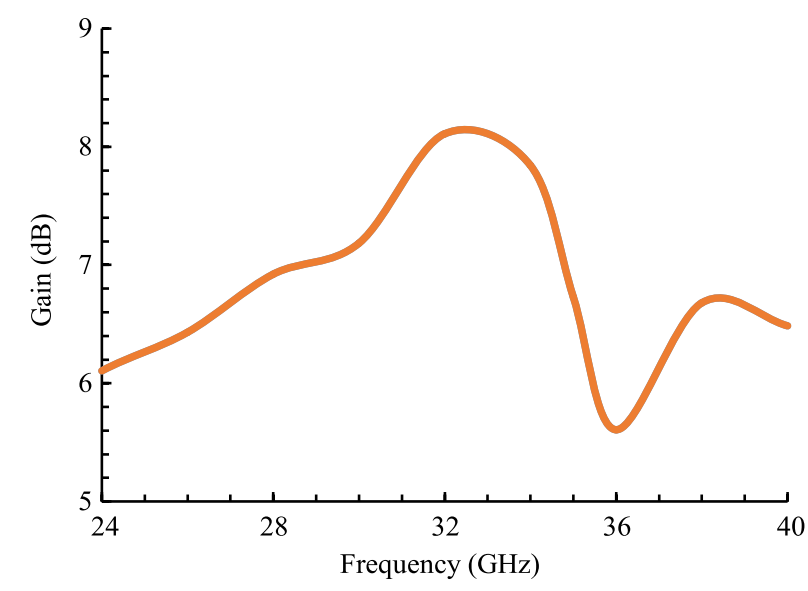

FIG. 8. GAIN VS FREQUENCY 


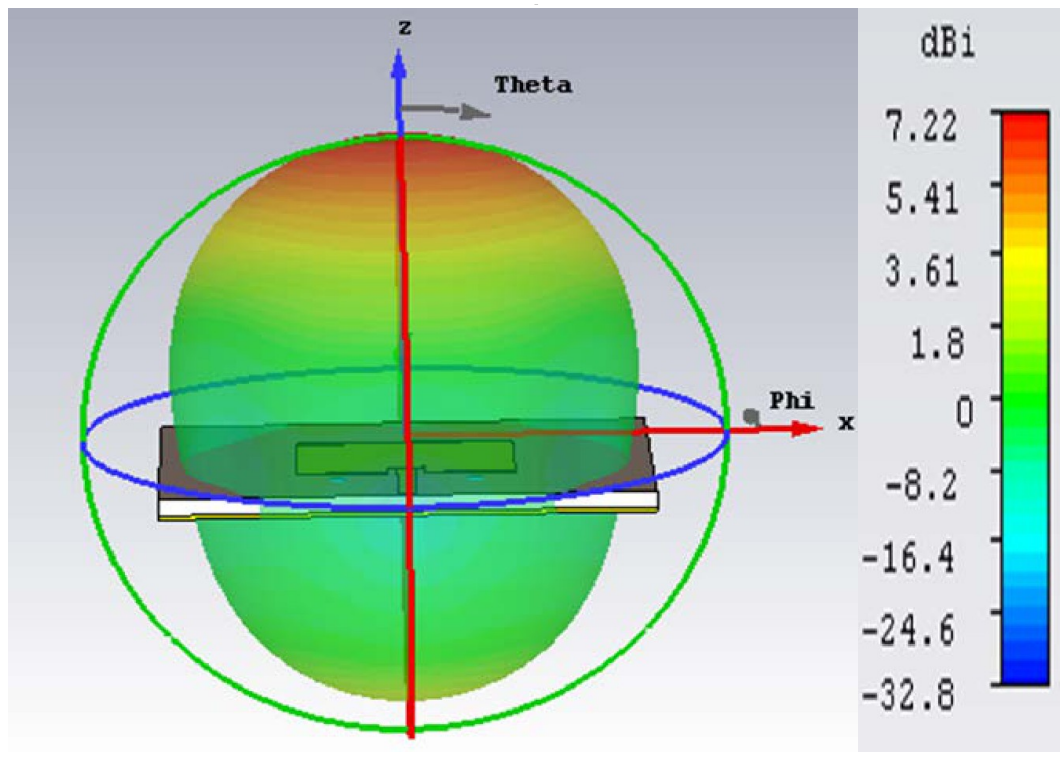

FIG. 9. 3D PLOT AT $28 \mathrm{GHZ}$

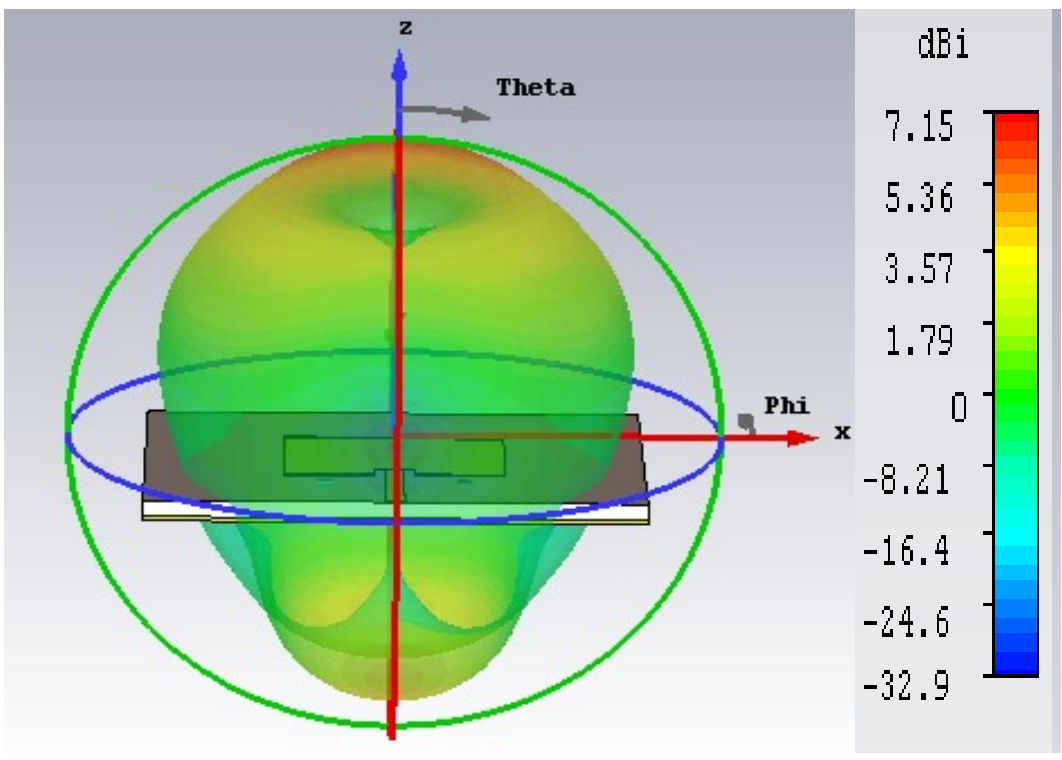

FIG. 10. 3D PLOT AT $38 \mathrm{GHZ}$

\section{CONCLUSION}

A frequency reconfigurable antenna for $5 \mathrm{G}$ mobile communications has been proposed in this research study. Simple six PIN diodes have been used to switch from one frequency band to other. It can cover a wide band from 25.6-39.3 GHz depending on diode states. It thus covers 28 and $38 \mathrm{GHz}$ that are expected to be the two key candidates for $5 \mathrm{G}$ communication. The gain ranges from 5.8-8.4dB for our proposed antenna. The efficiency is from $85-95 \%$ within the operating band. It has a compact size of $10.72 \times 7.42 \mathrm{~mm}^{2}$. Although being one of the smallest antenna of its type, it covers a wide band. Such a small size wide band reconfigurable antenna will be suitable for 5G hand held devices, networks and other applications. 


\section{ACKNOWLEDGMENTS}

Authors would like to express gratitude to all those who provided insight and expertise that helped to complete this research study.

\section{REFERENCES}

[1] Gupta, A., and Jha, R.K., "A Survey of 5G Network: Architecture and Emerging Technologies", IEEE Access, Volume 3, pp. 1206-1232, 2015.

[2] Rangan, S., Rappaport, T.S., and Erkip, E., "MillimeterWave Cellular Wireless Networks: Potentials and Challenges", Proceedings of IEEE Conference on Wireless Communications Network, Volume 102, No. 3, pp. 366- 385, 2014.

[3] Daniels, R.C., and Heath Jr, R.W., “60 GHz Wireless Communications: Emerging Requirements and Design Recommendations", IEEE Vehicular Technology Magazine, Volume 2, No. 3, pp. 41-50, 2007.

[4] Kestwal, M.C., Joshi, S., and Garia, L.S., "Prediction of Rain Attenuation and Impact of Rain in Wave Propagation at Microwave Frequency for Tropical Region", International Journal of Microwave Science and Technology, Article ID 958498, pp. 6, 2014

[5] Elkashlan, M., Duong, T.Q., and Chen, H.H., "Millimeter Wave Communications for 5G: Fundamentals", IEEE Communications Magazine, Volume 52, No. 9, pp. 52-54, 2014.

[6] Rappaport, T.S., Sun, S., Mayzus, R., Zhao, H., Azar, Y., Wang, K., Wong, G.N., Schulz, J.K., Samimi, M., and Gutierrez, F., "Millimeter Wave Mobile Communications for 5G Cellular: It Will Work!", IEEE Access, Volume 1, pp. 335-49, 2013.

Chen, Z.N., Liu, D., Nakano, H., Qing, X., and Zwick, T., "Handbook of Antenna Technologies", Springer, 2016.

[8] Bhellar, B., and Tahir, F.A., "Frequency Reconfigurable Antenna for Hand-Held Wireless Devices", IET Microwaves, Antennas \& Propagation, Volume 13, No. 9, pp.1412-1417, 2015.

[9] Monti, G., Corchia, L., and Tarricone, L., "A Microstrip Antenna with a Reconfigurable Pattern for RFID Applications", Progress in Electromagnetics Research, Volume 45, pp.101-116, 2012.
[10] Rafique, U., and Khalil, H., "Dual-Band Microstrip Patch Antenna Array for 5G Mobile Communications", Progress in Electromagnetics Research Symposium-Fall, pp. 55-59, November, 2017.

[11] Chen, Y., Ye, L., Zhuo, J., Liu, Y., Zhang, L., Zhang, M., and Liu, Q.H, "Frequency Reconfigurable Circular Patch Atenna with an Arc-Shaped Slot Ground Controlled by PIN Diodes", International Journal of Antennas and Propagation, pp. 1-7, 2017.

[12] Besoli, A.G., and De Flaviis, F., "A Multifunctional Reconfigurable Pixeled Antenna using MEMS Technology on Printed Circuit Board", IEEE Transactions Antennas and Propagation, Volume 59, No. 12, pp. 4413-4424, 2011.

[13] Arivazhagan, S., Ahila P.R., and Devi, V.S., "Design of a Reconfigurable Antenna for Cognitive Radio", IEEE International Conference on Electrical, Computer and Communication Technologies, pp.1-5, 2015

[14] Rouissi, I., Floc'h, J.M., Rmili, H., and Trabelsi, H., "Design of a Frequency Reconfigurable Patch Antenna Using Capacitive Loading and Varactor Diode”,IEEE 9th European Conference on Antennas and Propagation, pp.1- 4, 2015.

[15] Jilani, S.F., Greinke, B., Hao, Y., and Alomainy, A., "Flexible Millimeter Wave Frequency Reconfigurable Antenna for Wearable Applications in 5G Networks", URSI International Symposium on Electromagnetic Theory, pp. 846-848, 2016.

[16] Doherty, W.E., and Joos, R.D., "The PIN Diode Circuit Designers’ Handbook”, Microsemi Corporation, 1998.

[17] Yang, X.L., Lin, J.C., Chen, G., and Kong, F.L., "Frequency Reconfigurable Antenna for Wireless Communications Using GaAs FET Switch", IEEE Antennas and Wireless Propagation Letters, Volume 14, pp. 807-810, 2015.

[18] Pendharker, S., Shevgaonkar, R.K., and Chandorkar, A.N., "Optically Controlled Frequency-Reconfigurable Microstrip Antenna with Low Photoconductivity", IEEE Antennas and Wireless Propagation Letters, Volume 13, pp. 99-102, 2014.

[19] Ge, L., and Luk, K.M., "Frequency Reconfigurable LowProfile Circular Monopolar Patch Antenna", IEEE Transactions on Antennas and Propagation, Volume 62, No. 7, pp. 3443-3449, 2014.

[20] CST Computer Simulation Technology, CST Microwave Studio, 2015. 